\title{
RL10 Engine Ability to Transition from Atlas to Shuttle/Centaur Program
}

\author{
Joseph F. Baumeister ${ }^{\mathrm{I}}$ \\ NASA Glenn Research Center, Cleveland, OH 44135
}

\begin{abstract}
A key launch vehicle design feature is the ability to take advantage of new technologies while minimizing expensive and time consuming development and test programs. With successful space launch experiences and the unique features of both the National Aeronautics and Space Administration (NASA) Space Transportation System (Space Shuttle) and Atlas/Centaur programs, it became attractive to leverage these capabilities. The Shuttle/Centaur Program was created to transition the existing Centaur vehicle to be launched from the Space Shuttle cargo bay. This provided the ability to launch heaver and larger payloads, and take advantage of new unique launch operational capabilities. A successful Shuttle/Centaur Program required the Centaur main propulsion system to quickly accommodate the new operating conditions for two new Shuttle/Centaur configurations and evolve to function in the human Space Shuttle environment. This paper describes the transition of the Atlas/Centaur RL10 engine to the Shuttle/Centaur configurations; shows the unique versatility and capability of the engine; and highlights the importance of ground testing. Propulsion testing outcomes emphasize the value added benefits of testing heritage hardware and the significant impact to existing and future programs.
\end{abstract}

\section{Nomenclature}

$\begin{array}{ll}\text { LH2 } & =\text { liquid hydrogen } \\ \text { LOX } & =\text { liquid oxygen } \\ \text { O/F } & =\text { oxidizer fuel ratio } \\ \text { ONPSP } & =\text { oxidizer net positive suction pressure } \\ \text { OPIP } & =\text { oxidizer pump inlet pressure } \\ \text { TDRSS } & =\text { Tracking and Data Relay Satellite System }\end{array}$

\section{Introduction}

NASA's Centaur vehicle was the first of a new generation of space vehicle upper-stage rockets that pioneered the use of liquid hydrogen fuel for space flight. The Centaur upper-stage was developed by NASA Lewis Research Center, now Glenn Research Center in Cleveland, Ohio. The Centaur became the world's first high-energy upperstage, burning liquid hydrogen (LH2) and liquid oxygen (LOX) to place payloads in geosynchronous orbits or to provide escape velocity for interplanetary space probes. In combination with the RL10 engine (currently manufactured by Aerojet Rocketdyne), the Centaur became the highest performing upper-stage and one of the most prominent launch vehicles in America's exploration of space. The vehicle has more than 200 launches that included sending the Voyager spacecraft to the outer planets, Viking landers to the surface of Mars, Cassini to Saturn, and the New Horizons probe to Pluto. The Centaur Vehicle was developed and manufactured by General Dynamics / Astronautics under the direction of NASA's Lewis Research Center. ${ }^{1}$

The Centaur Program started in 1958 with its first successful flight in November 27, 1963 at Cape Canaveral Air Force Station in Florida. Since then the vehicle has undergone numerous evolutionary upgrades and modification to improve its performance, operability, and reliability. From 1966 to 1989, the Centaur-D configuration was used as the upper-stage for 63 Atlas rocket launches (55 successful launches). Today the Atlas/Centaur has evolved into a

\footnotetext{
${ }^{\mathrm{I}}$ Aerospace Engineer, NASA Glenn Research Center, Propulsion Division, 21000 Brookpark Rd., Cleveland, OH, 44135.
} 
suite of Atlas supported vehicles launching from both Cape Canaveral Air Force Station and Vandenberg Air Force Base.

Hydrogen in its natural state is a gas and is the lightest and simplest of all elements. Liquid hydrogen is colorless, odorless, and very lightweight. To remain in a liquid state, hydrogen must be kept supercooled to $-423{ }^{\circ} \mathrm{F}$ $\left(-253{ }^{\circ} \mathrm{C}\right)$. For the Centaur to accommodate liquid hydrogen, new technologies were required. This included developing a highly integrated propellant storage and utilization system that included thermal insulation, propellant feed system and propulsion capable engines. It also required appropriate hydrogen ground handling and controls. This lightweight Centaur vehicle with engines that utilized liquid hydrogen and oxygen mixture could then deliver about 35 percent more thrust per pound of propellant than other conventional kerosene-type fuels.

The RL10 propulsion engine was a major sub-system in the successful Centaur Program and continues to provide sustained reliability and performance. Its efficiency and capabilities have kept the Centaur in the forefront of space flight. Integrating the existing Centaur RL10 engine within the Space Shuttle was a cornerstone of the Shuttle/Centaur Program. The RL10 operational flexibility enabled easy transition with minimal modifications and the ability to transition to a human space flight environment. We will explore the differences between the Atlas/Centaur and Shuttle/Centaur vehicles, impacts on the propulsion system, and the role ground testing provided.

\section{Atlas/Centaur Vehicle Configuration}

The Atlas/Centaur is an expendable launch vehicle derived from the SM-65D Atlas intercontinental ballistic missile in the late 1950s. The Atlas boosters were developed by the United States Air Force and were repurposed for NASA's Atlas/Centaur Program. The Atlas first stage booster rocket was mated to the new Centaur liquid-hydrogen and liquid-oxygen cryogenic fueled upper stage. This high-energy Centaur upper-stage was capable of placing much heavier payloads into higher earth orbits, unmanned lunar trajectories, or planetary trajectories by incorporating the new RL10 propulsion system. This Atlas/Centaur design is shown in Fig. 1 \& 2. The Atlas/Centaur-2 launch demonstrated a successful Centaur vehicle separation and flight with the first RL10 engine inflight burn of liquid hydrogen and liquid oxygen. The Centaur vehicle had an extraordinary operational success record and has been called "America's Workhorse in Space".

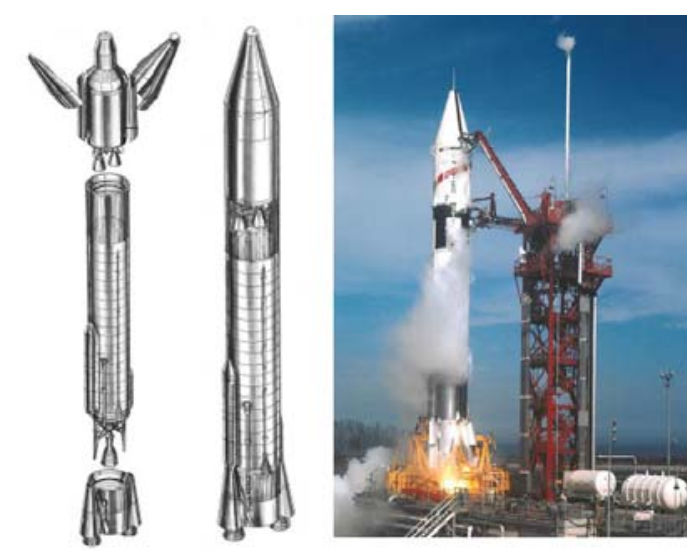

Figure 1. Atlas/Centaur Configuration and Atlas/Centaur-2 Launch.

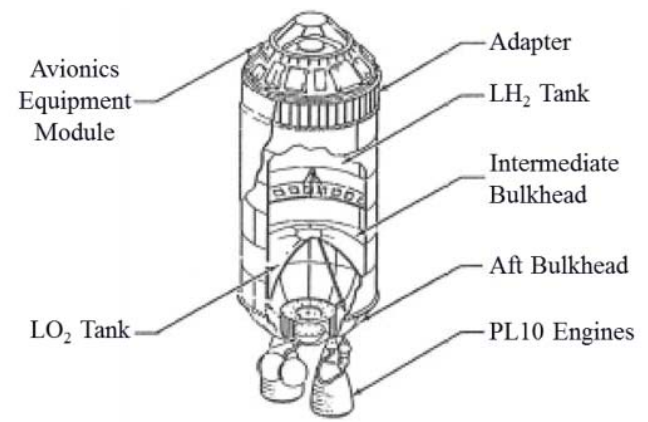

Figure 2. Early Centaur Configuration. 
The Centaur D-1 vehicle was 29 feet in length and had a diameter of 10 feet with all avionics and payload mounted on the forward adapter. It had no internal support structure and was pressurized to maintain it shape and strength. The thrust was obtained from two RL10 engines that generate 15,000 nominal pounds of thrust each. These engines were capable of being shut-down and restarted during flight to increase mission capability and were gimbaled to provide spacecraft directional control. Figure 3 shows the Centaur engine configuration as the vehicle is being lowered into a NASA Lewis Research Center Test facility. In addition, smaller hydrogen peroxide engines provided additional thrust for propellant settling and attitude control during transition and low thrust coast periods. This vehicle had the capability of lifting over 8000 pound payloads into near Earth orbits, 2300 pounds to the Moon, and boosting 1300 pounds on interplanetary trajectories. Unique Centaur design features and upgrades included:

- Thin wall stainless steel tanks (lightweight). Structural rigidity was provided by propellant pressure (prior to propellant loading, nitrogen gas pressurization provided structural support).

- A common double-bulkhead to separate the LOX and LH2 tanks.

- Multiple engine restart vehicle.

- Hydrazine monopropellant reaction control system (previously a hydrogen peroxide system).

- Tank pressure from RL10 boost pumps (previous hydrogen peroxide system).

- Centaur powered by one or two RL10 rocket engines.

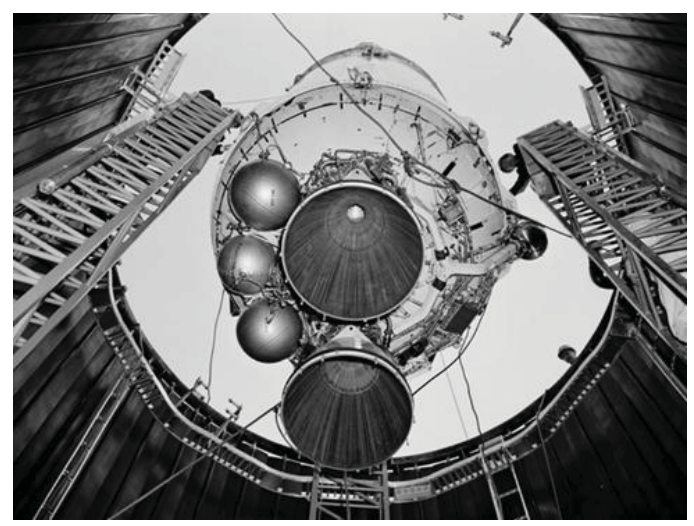

Figure 3. Atlas/Centaur Being Lowered into NASA Lewis Research Center Test Facility.

\section{Titan-Centaur Vehicle Configuration}

The Centaur was also successfully integrated with the United States Air Force Titan vehicle known as Titan IIIE. The Centaur was modified to be used as the third stage on the Titan IIIE vehicle. From 1974 to 1977, the Centaur D1T configuration launches included the Viking $1 \& 2$, Voyager $1 \& 2$, and Helios $1 \& 2$. Figure 4 shows the Titan/Centaur configuration.
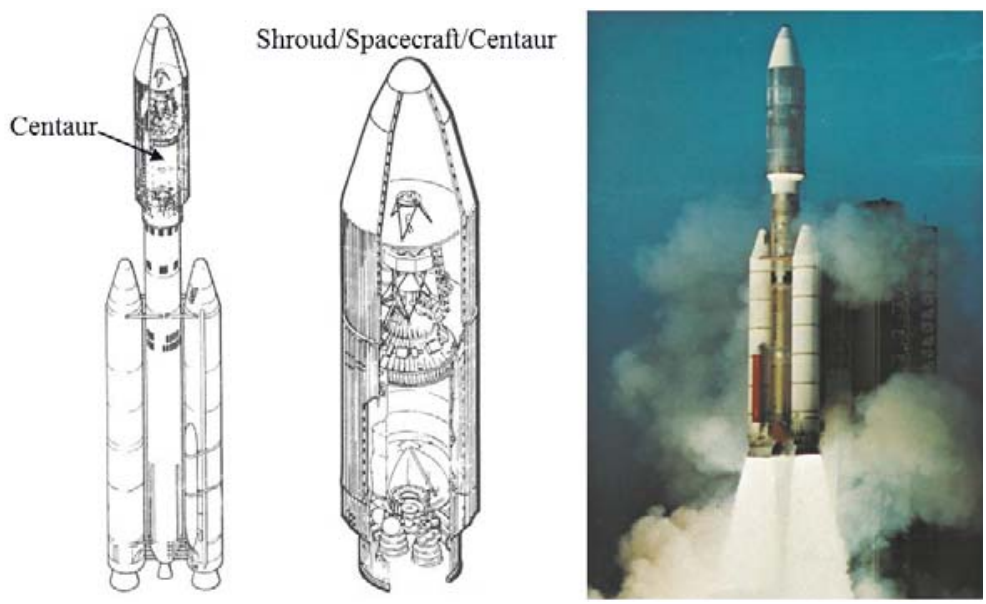

Figure 4. Titan/Centaur Vehicle (Left), Centaur and Payload (Middle), August 20, 1975 Titan Centaur Launch of Viking 1 Spacecraft (Right). 


\section{Centaur RL10 Engines}

The RL10 engine was designed as a regeneratively cooled system (hydrogen cooled thrust chamber) which included a turbo-pump that utilized an expander cycle (thrust chamber expanded hydrogen to power turbo-pump). ${ }^{2}$ The original Centaur engines flown on the first successful Atlas/Centaur flight were designated as the RL10A-3 engines. Over the years, prior to the Shuttle/Centaur Program, the engines were upgraded to enhance vehicle performance, shown in Table 1. The engine is shown in Fig. 5.

Table 1. Early RL10 Engine Performance Upgrades.

\begin{tabular}{|l|c|c|c|c|c|}
\cline { 2 - 6 } \multicolumn{1}{c|}{} & \multicolumn{5}{c|}{ RL10 Model Number } \\
\cline { 2 - 6 } \multicolumn{1}{c|}{} & RL10A-1 & RL10A-3 & RL10A-3-1 & RL10A-3-3 & RL10A-3-3A \\
\hline Thrust, lbs. (Vacuum) & 15,000 & 15,000 & 15,000 & 15,000 & 16,500 \\
\hline ISP, sec. (5.0 Mixture) & 424 & 429 & 433 & 444 & 446.4 \\
\hline Chamber Pressure, psia & 300 & 300 & 300 & 395 & 465 \\
\hline Throat Diameter, in. & 6.0 & 6.0 & 6.0 & 5.1 & 4.9 \\
\hline Expansion Ratio & $40: 1$ & $40: 1$ & $40: 1$ & $57: 1$ & $61: 1$ \\
\hline Engine Envelope, in. & $\begin{array}{c}70 \text { long } \\
40 \text { wide }\end{array}$ & \multirow{2}{*}{ Unchanged } & Unchanged & \multirow{2}{*}{ Unchanged } & \multirow{2}{*}{ Unchanged } \\
\hline
\end{tabular}

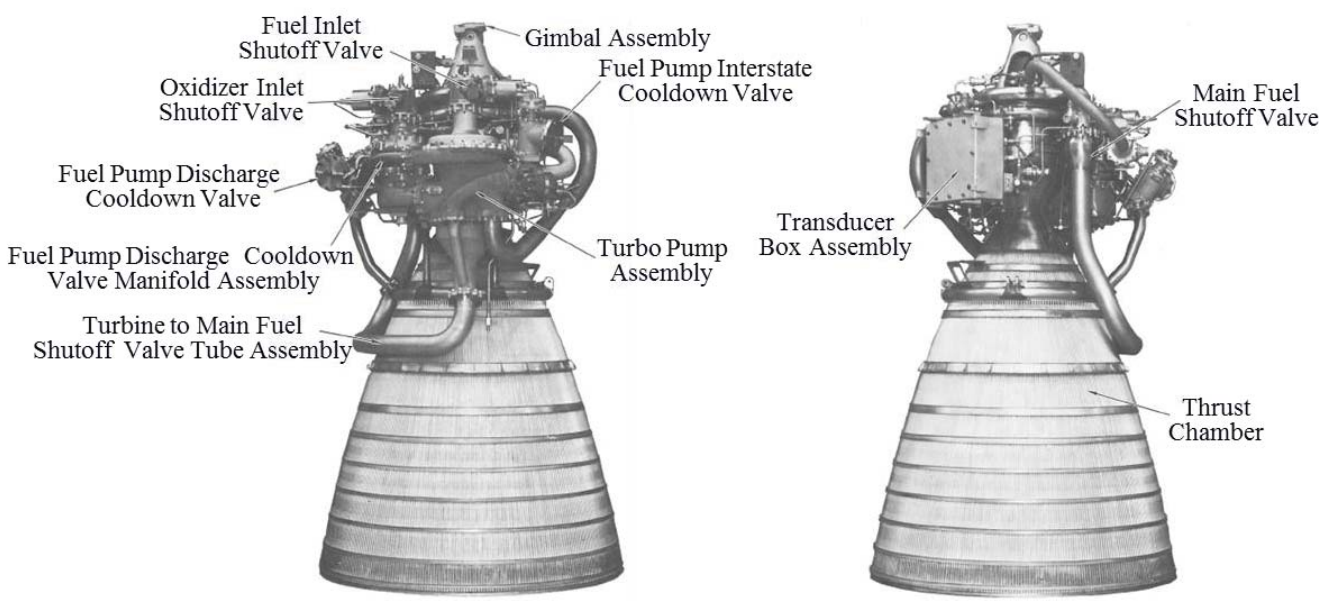

Figure 5. RL10A-3-3A Engine Side Views.

Each Centaur RL10A-3-3A engine at space vacuum conditions produced a rated thrust of 16,500 pounds and a $444.4 \pm 2.5 \mathrm{sec}$ nominal specific impulse at a nominal propellant oxidizer to fuel mixture ratio of 5.0:1. The engines also gimbal which provides flight control, are capable of inflight restarts, and provide a small amount of hydrogen gas for vehicle fuel tank pressurization. Solenoid valves which control the flow of vehicle helium to pressure actuated valves provide engine control for component chill down, engine start, and shutdown. Chill down of the engine pumps is required prior to engine start. ${ }^{3}$ Additional features include:

- Turbo-pump supplies both hydrogen and oxygen to the combustion chamber.

- Thrust Chamber has 180 short and 180 tapered tubes for nozzle cooling and expands hydrogen to power the turbo-pump.

- Engine thrust is regulated by the Thrust Control Valve.

- Propellant mixture ratio regulated by the Oxidizer Flow Control Valve.

- $\quad$ Engines may gimbal \pm 4 degrees.

\section{Shuttle/Centaur Program}

Integrating the Space Shuttle with the high-energy Centaur upper-stage provided a broad range of new space flight possibilities. This included launching heavier and larger spacecraft, the potential to checkout and service the spacecraft prior to separation, and even return the spacecraft to earth if necessary. Figure 6 represents a Centaur deployment and Fig. 7 highlights the major Shuttle/Centaur systems. The Shuttle/Centaur Program began in 1982 as a requirement for the upcoming Galileo and European Space Agency's Ulysses spacecraft missions in 1986 and 
resulted in a partnership between NASA and the United State Air Force. The first planned missions included Galileo, Ulysses, Magellan, International Solar Polar Mission and Department of Defense missions. With the Shuttle/Centaur increased payload capabilities and unique mission flexibility, it positioned the United States to continue its leadership in launch vehicles. If not for the tragic Space Shuttle Challenger, the Shuttle/Centaur may have changed spaceflight as we know it today.

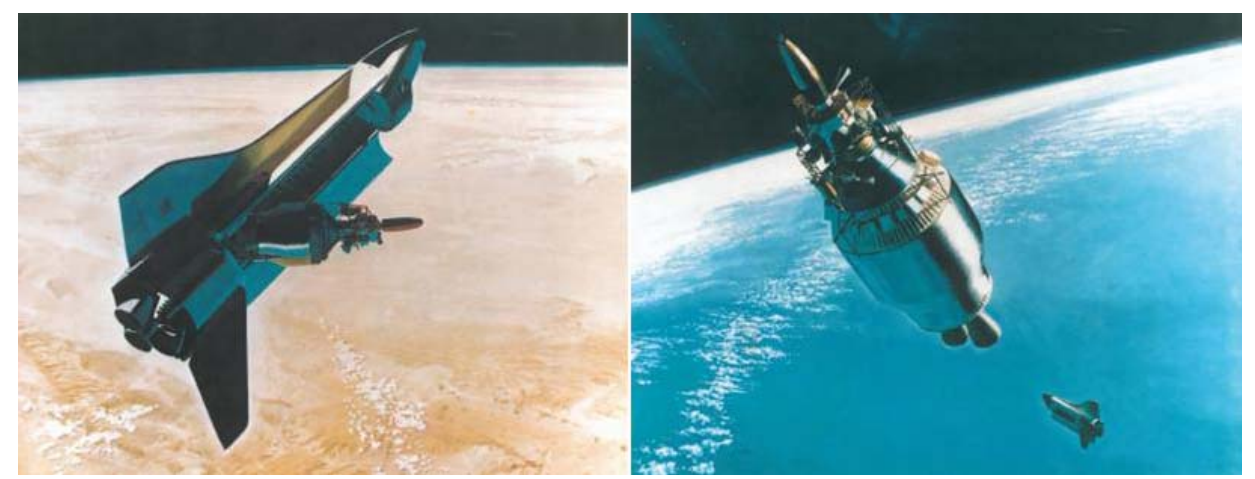

Figure 6. Shuttle/Centaur Deployment.

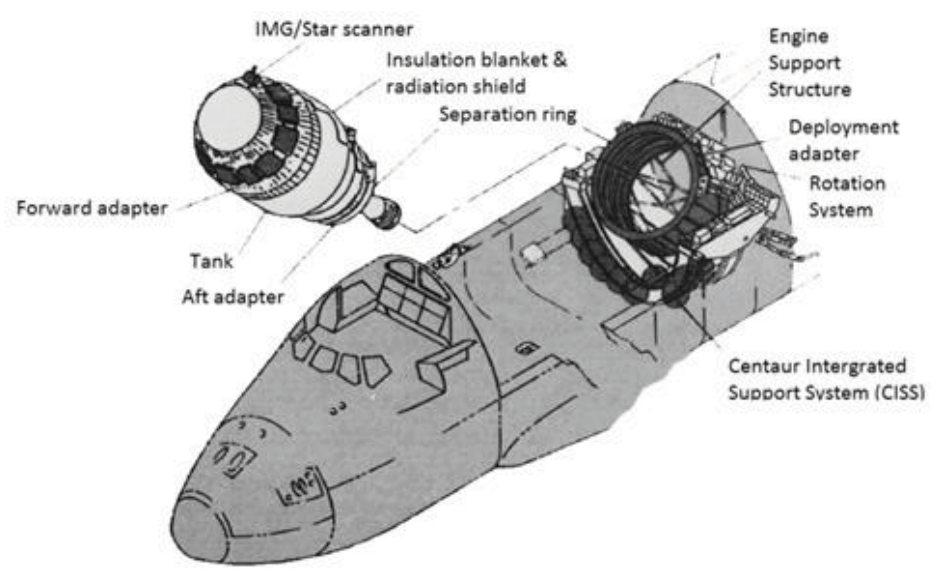

Figure 7. Shuttle/Centaur Hardware Configuration.

Major Shuttle/Centaur Program requirements were:

- General Requirements:

- Design \& develop a high-energy upper-stage for use with the Space Shuttle.

- Develop two versions to maximize launch capabilities.

- $\quad$ NASA Specific Requirements

- Meet new interplanetary velocity requirements.

- Accommodate a 30 foot payload.

- Support the Galileo \& International Solar Polar missions in 1986.

- United States Air Force Specific Requirements

- $10,000 \mathrm{lbs}$. to geosynchronous orbit.

- $11,500 \mathrm{lbs}$. to 12 -hr orbit (Molniya orbits).

- Accommodate a 40 foot payload in orbiter bay.

In order to take full advantage of the Space Shuttle platform, the Centaur (based on the Centaur D-1A vehicle) needed to be resized, develop a Space Shuttle deployment system, make appropriate Centaur modifications, and ensure the Centaur addresses all human space flight requirements. This resulted in developing two new vehicles, the Centaur G and Centaur G-prime vehicles. Table 2 shows both integrated Centaur and Centaur Integrated Support System (CISS) configurations and dimensions. Each vehicle provided payload flexibility depending on the mission needs. The G-Prime vehicle was designed to hold 54\% more propellant than Centaur D-1A. 
Table 2. Shuttle/Centaur and CISS Configurations.

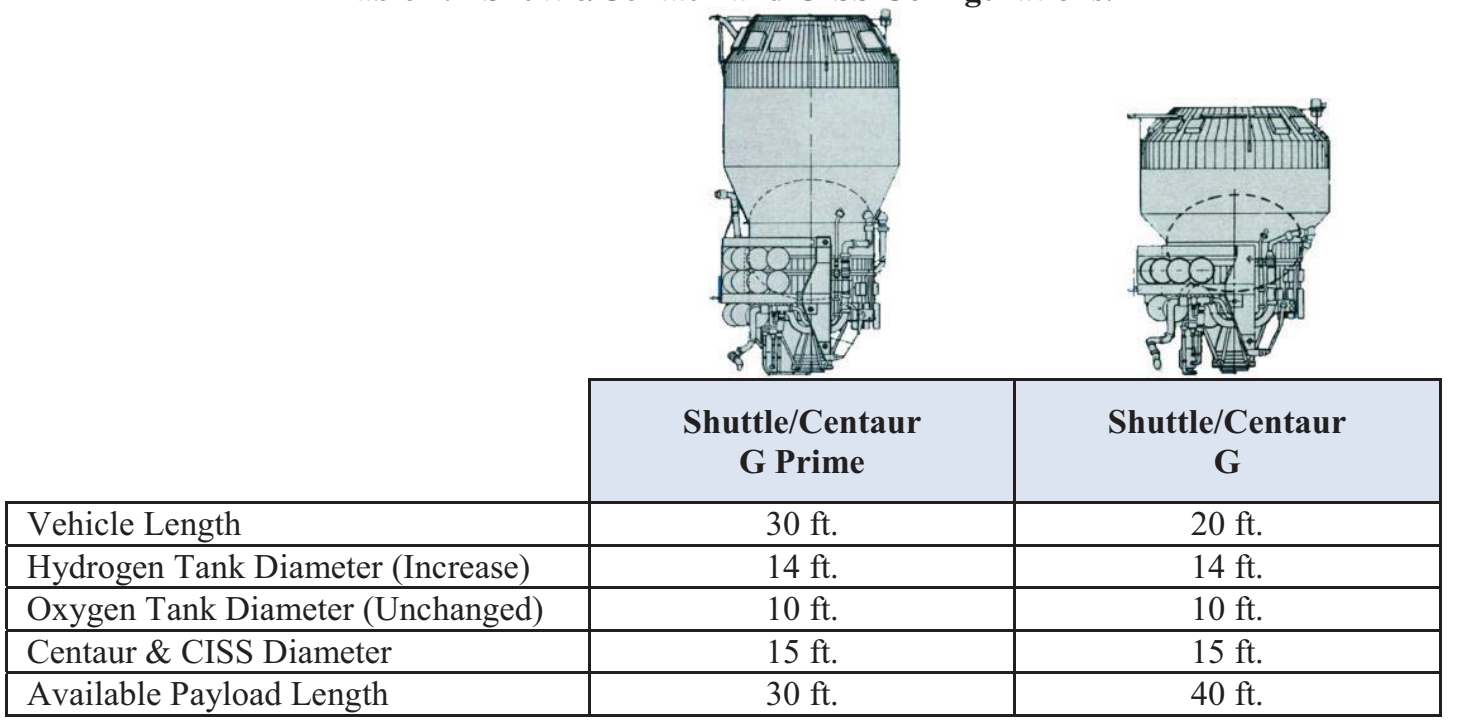

Centaur modifications were implemented to accommodate Space Shuttle integration and to take advantage of new technologies, which included:

- New 170 inch diameter LH2 tank cylindrical section \& insulation.

- New conical transition to LH2 tank.

- $\quad$ LH2 and LOX tank lengths are dependent on vehicle and engine burn mixture ratio.

- $\quad$ New TDRSS-compatible S-band transmitter \& RF system.

- Dual failure-tolerant arm/safe unit.

- $\quad$ Added star scanner (optional).

- $\quad$ Forward adapter (composite stub adapter).

- New propellant dump system for aborts.

- $\quad$ New aft adapter (composite skin) \& separation ring.

- Integrate the Centaur and Space Shuttle with the Centaur Integrated Support System (CISS).

The CISS was a major systems development activity for the program. The CISS was integrated with the Space Shuttle to provide the means to support the Centaur during Space Shuttle flights, the ability to control and release the Centaur, and supported all functions in the event of a return to earth scenario. This included supporting all the pre-launch operations, controlling Centaur pressurization, and providing a means for propellant dumps in the event of a Centaur Launch Abort. Figure 8 provides the Shuttle/Centaur Program integrated schedule.

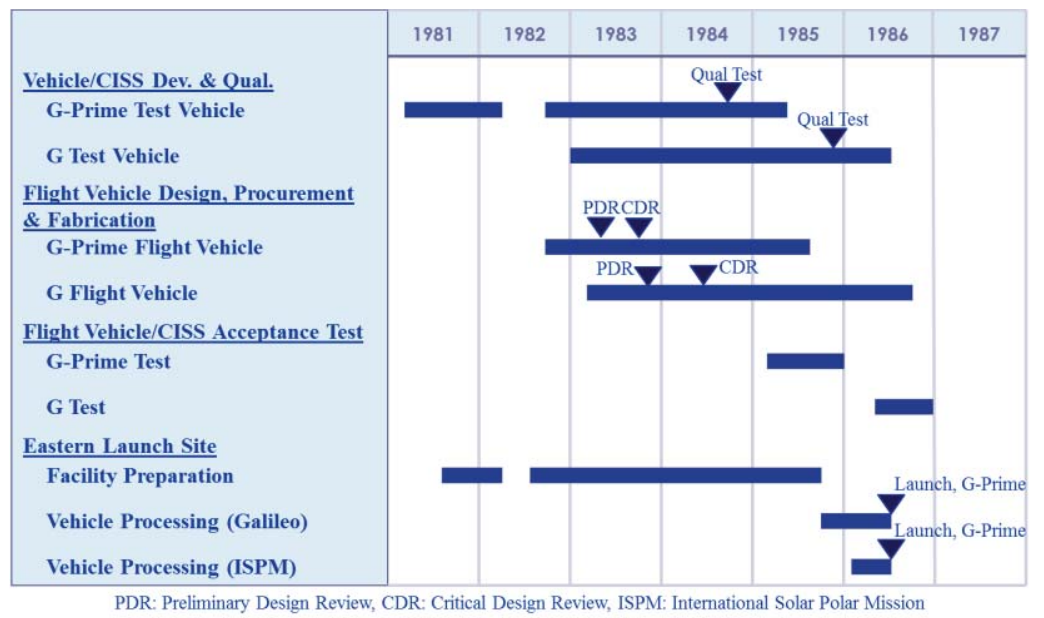

Figure 8. Shuttle/Centaur Integrated Schedule.

American Institute of Aeronautics and Astronautics 
Key to the Shuttle/Centaur Program was the propulsion system's ability to transition with minimal changes. This included accommodating the new Space Shuttle environments, new operating constraints, supporting two new Centaur configurations, new Space Shuttle launch loads, two different engine propellant mixture ratios, modifying prelaunch cooling, and accommodating new vehicle interfaces features. Table 3 lists significant nominal vehicle and engine characteristics. ${ }^{4}$

Table 3. Nominal Vehicle and Engine Characteristics.

\begin{tabular}{|c|c|c|}
\hline $\begin{array}{c}\text { Atlas/Centaur } \\
\text { (D-1) }\end{array}$ & $\begin{array}{c}\text { Shuttle/Centaur } \\
\text { G Prime }\end{array}$ & $\begin{array}{c}\text { Shuttle/Centaur } \\
\text { G }\end{array}$ \\
\hline RL10A-3-3A & RL10A-3-3A & RL10A-3-3B \\
\hline \multicolumn{3}{|c|}{} \\
\hline 24,700 & 38,000 & 25,000 \\
\hline 5,100 & 7,500 & 4,000 \\
\hline \multicolumn{3}{|c|}{} \\
\hline $16,500 \pm 300$ & $16,500 \pm 300$ & $15,000 \pm 300$ \\
\hline $444.4 \pm 2.5$ & $444.4 \pm 2.5$ & $436.0 \pm 2.7$ \\
\hline $5.0: 1$ & $5.0: 1$ & $6.0: 1$ \\
\hline $4.4: 1$ to $5.6: 1$ & $4.4: 1$ to $5.6: 1$ & $5.4: 1$ to $6.7: 1$ \\
\hline 6.2 lbs./sec. & 6.2 lbs./sec. & $4.9 \mathrm{lbs} /$ sec. \\
\hline $31.0 \mathrm{lbs} . / \mathrm{sec}$. & $31.0 \mathrm{lbs} / \mathrm{sec}$. & $29.3 \mathrm{lbs} /$ sec. \\
\hline 474 & 474 & 474 \\
\hline \multicolumn{3}{|c|}{} \\
\hline Below $75^{\circ} \mathrm{R}$ & None & None \\
\hline Below $270{ }^{\circ} \mathrm{R}$ & None & None \\
\hline
\end{tabular}

To accommodate the Space Shuttle safety requirement of no propellants at the engine interface, the Shuttle/Centaur Program modified the ducts and added valves for propellant isolation. This required introducing two new valves with demanding temperature and leakage requirements, Fig. 9.
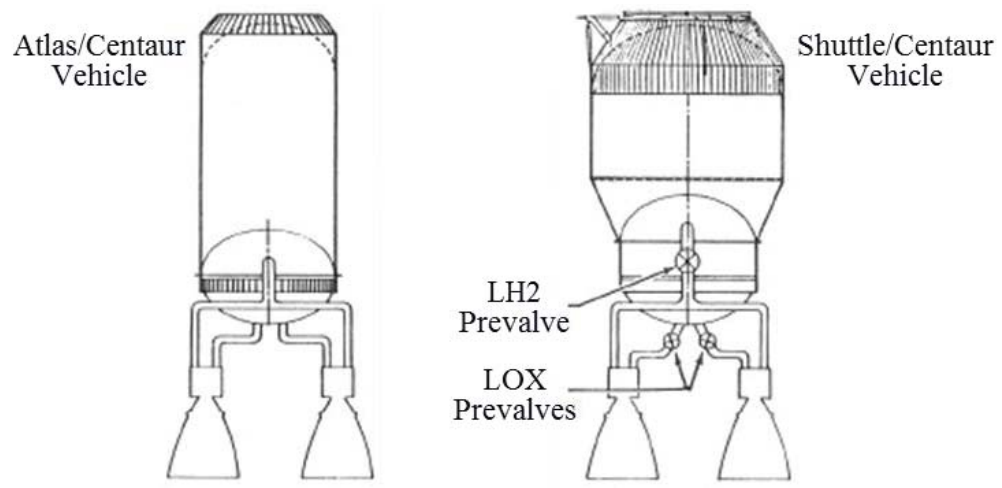

Figure 9. Centaur Ducts and Pre-Valve Modifications.

Integrating the prevalves into the Shuttle/Centaur configuration required a new method of efficiently providing necessary temperature conditioning prior to engine start (to prevent pump cavitation during engine start, referred to as cooldown). This resulted in a major change in the engine start cooldown process and inlet conditions. 
$\underline{\text { Atlas/Centaur }}$

- Ducts Full (Cold)

- Engine Inlet Valves mounted immediately upstream of turbo-machine

- Prelaunch Cooldown (ground supplied Liquid $\mathrm{He}$ )

- Engine Start: 4.5 minutes into Launch

- Short Prestart Cooldown $\underline{\text { Shuttle/Centaur }}$

- Ducts Empty (Warm)

- Pre-valves added upstream of engine

- No Prelaunch Cooldown

- Engine Start: Range from Hours to Days

- Utilize Propellant to Cool Ducts and TurboMachinery

- Long First Burn Prestart Cooldown

In addition, the RL10 engine had to accommodate the Space Shuttle Program human space flight requirements that included:

- $\quad$ Space Shuttle Program Requirements.

- $\quad$ Payloads Safety Policy and Requirements.

- Safety, Reliability, Maintainability and Quality Provisions.

- $\quad$ Requirements for Soldered Electrical Connections.

- Launch site Accommodations.

- Contamination Control Requirements.

\section{Major Launch Event Differences Between the Atlas and Shuttle/Centaur Propulsion Systems}

The following highlights major Atlas and Shuttle/Centaur engine flight event and procedure differences.

\section{A. Prelaunch Cooldown}

The Atlas/Centaur Program utilized unique engine hardware and ground support equipment to introduce ground supplied cold helium gas to cool the turbo-pump assembly. This was designed to minimize inflight cooldown time and propellants. Prior to launch, the fuel and oxidizer pumps were maintained below 75 degrees Rankin and 270 degrees Rankin respectively and the fuel and oxidizer ducts were cold from the propellants in the ducts. The Shuttle/Centaur Program did not accommodate these features.

\section{B. Boost Flight Phase}

Atlas/Centaur had propellant and pneumatic power at its engine interfaces. Due to Space Shuttle safety requirements, the Shuttle/Centaur engines were inactive and all propellants and pneumatic power were not permitted at engine interfaces. This required the Shuttle/Centaur Program to place additional valves in the propellant feed system to isolate the propellants and engines.

\section{Separation}

Atlas/Centaur immediately began prestart procedures after stage separation. Following Shuttle/Centaur separation, the Centaur coasts for 45 minutes before pneumatic power and propellants were provided to the engine interface.

\section{Prestart}

Atlas/Centaur engine inlet valves were opened immediately after staging with the oxidizer flowing for nine seconds and the fuel for five seconds to provide cooldown prior to engine start. This rapid conditioning was needed while the vehicle was under low thrust and influence of the earth's gravity prior to reaching orbit. The Space Shuttle delivers the Shuttle/Centaur vehicle into a stable obit so rapid engine conditioning was not a requirement. It did however; require additional propellant to properly condition the duct and turbo-pumps due to higher temperatures.

\section{E. Start}

Both the Atlas and Shuttle/Centaur had common engine start procedures. The Shuttle/Centaur added a dual pressure switch ignition system in the ignition exciter box to provide redundancy for indicating if acceptable internal pressure was maintained. Table 4 identifies the RL10 nominal engine requirements for both the G Prime and G vehicle. 
Table 4. Nominal Shuttle/Centaur Engine Start Requirements.

\begin{tabular}{|c|c|c|}
\hline & & \\
\hline & $\begin{array}{c}\text { Shuttle/Centaur } \\
\text { G Prime }\end{array}$ & $\begin{array}{c}\text { Shuttle/Centaur } \\
\text { G }\end{array}$ \\
\hline Engine: & RL10A-3-3A & RL10A-3-3B \\
\hline Number of Engine Starts & 1 & 2 \\
\hline Burn Time & $650 \mathrm{sec}$. & $450 \mathrm{sec}$ \\
\hline Engine Start, Nominal: & & \\
\hline Fuel Pump Inlet Temperature & $38.5^{\circ} \mathrm{R}$ & $38.5^{\circ} \mathrm{R}$ \\
\hline Fuel Pump Inlet Pressure & $29.8 \mathrm{psia}$ & $36.0 \mathrm{psia}$ \\
\hline Oxidizer Pump Inlet Temperature & $175.7^{\circ} \mathrm{R}$ & $174.5^{\circ} \mathrm{R}$ \\
\hline Oxidizer Pump Inlet Pressure & 47.7 psia & $39.0 \mathrm{psia}$ \\
\hline Steady State, Nominal: & & \\
\hline Liquid Fuel Flow & $6.2 \mathrm{lbs} . / \mathrm{sec}$ & $4.9 \mathrm{lbs} . / \mathrm{sec}$ \\
\hline Liquid Oxidizer Flow & $31.0 \mathrm{lbs} . / \mathrm{sec}$ & $29.3 \mathrm{lbs} . / \mathrm{sec}$ \\
\hline
\end{tabular}

\section{F. Restart}

Both the Atlas and Shuttle/Centaur had similar restart sequences with the ability to accommodate different cooldown times. The G-Prime vehicle required only one engine start (one engine burn to boost payloads into high energy interplanetary trajectories). The $\mathrm{G}$ vehicle required two engine starts (place payloads into geosynchronous orbit). Additional engine restart capabilities were available if needed.

\section{G. Mission Aborts}

The Space Shuttle provided the ability to abort the Centaur separation, dump propellants, and return the payload and vehicle back to earth. The RL10 engines were required to be reusable following a return to earth abort.

With the program dependent on meeting the upcoming mission launch windows, program success was directly tied to timely and successful testing to verify and validate engine performance. NASA management initiated a variety of testing activities to accommodate Shuttle/Centaur propulsion changes. The testing focused on the Shuttle/Centaur Program, but it also set the stage for future advanced engine developments, applications and unique operations.

\section{Shuttle/Centaur Engine Testing}

The Space Shuttle payload volume provided the opportunity to maximize the Centaur's mission capabilities by accommodating two Centaur configurations with different RL10 engine configurations and operating conditions. The vast majority of the Atlas/Centaur to Shuttle/Centaur transition required minimal hardware modifications. But management's decision to perform a series of program related engine testing proved to be extremely valuable. The following summarizes major ground testing activities performed for the program.

\section{A. RL10 Pre Start Engine Conditioning Testing}

Whereas the Atlas/Centaur vehicle benefited from both cold propellants in the ducts and prelaunch cooldown procedures, the Shuttle/Centaur now had empty ducts while maintaining the ducts and engines at higher temperatures. With the need to condition the propellant lines and engine pump temperatures prior to engine start, a test program was conducted to demonstrate the ability to operate under these new conditions. ${ }^{5}$ Testing focused on the new expanded inlet conditions and new cooldown requirements while trying to minimize propellant consumption. The expanded inlet test program was conducted to define the RL10A-3-3A engine start characteristics for the Shuttle/Centaur G-Prime vehicle and the RL10A-3-3B engine start characteristics for the Shuttle/Centaur G vehicle. It also presented a new set of testing issues to accurately represent flight conditions during ground testing of flow through empty propellant ducts with gravity effects. Therefore, verification would require a combination of analysis with component and engine testing.

The existing RL10 engine test stand required integrating the new Shuttle/Centaur prevalves and building the propellant ducts to best simulate flight hardware. The oxidizer duct was identical to the flight unit and the fuel Y- 
duct configuration was only a single path duct. Each maintained flight design wall thickness, gimbal joints and bellows, and appropriate foam and Mylar insulation, as shown in Fig. 10 and Fig. 11. Testing of cooldown time and propellant consumption was performed for various inlet conditions and compared to calculated values.
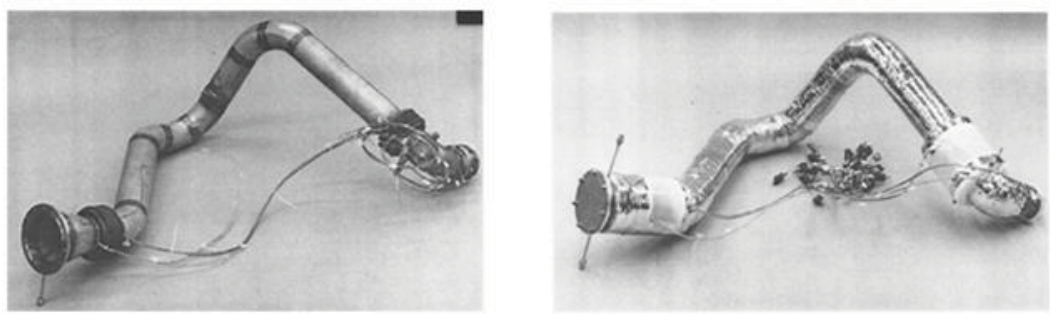

Figure 10. Fuel Duct Instrumented with Skin Thermocouples (Left), Insulated (Right).
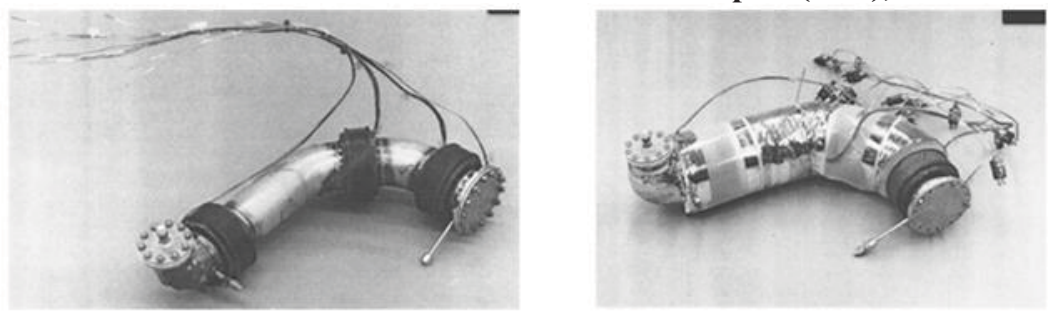

Figure 11. Oxidizer Duct Instrumented with Skin Thermocouples (Left), Insulated (Right).

Testing revealed that the effect of gravity decreased the duct cooldown efficiency, particularly on the oxidizer duct, due to propellant traveling along the bottom surface of the horizontal duct and vapor cooling the upper surface. This resulted in a temperature variation of over 150 degrees Rankin and gas being trapped. This required retesting in a rig in a vertical orientation.

The final test outcomes for both engine configurations were:

- Successful engine start over the expanded inlet conditions for both missions.

- $\quad$ Reduced propellant consumption if engine cooldown flow areas were significantly reduced (reducing cooldown valves flow areas) and flow time was increased.

- New engine start characteristics where successfully tested with cooldown changes, Fig. 12.

- Cooldown changes on engine acceleration were acceptable, Fig. 13.

- Water-hammer tests for worst case conditions were acceptable.

- $\quad$ Qualification testing was defined.
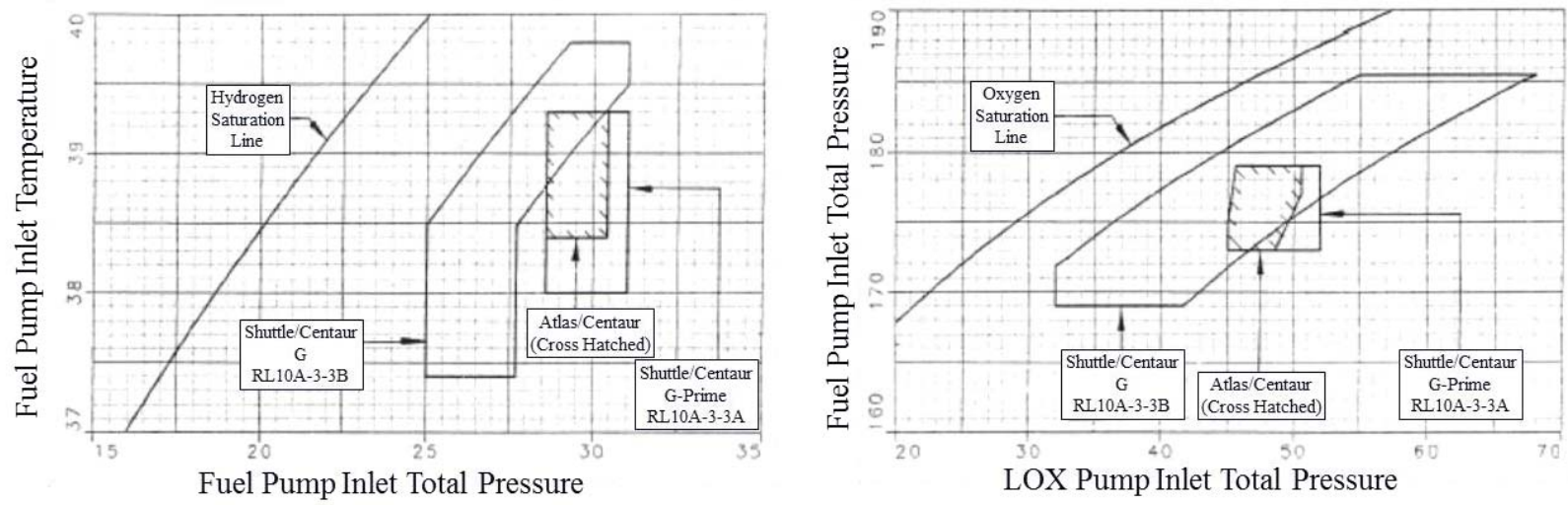

Figure 12. Fuel and Oxidizer Pump Start Envelopes. 


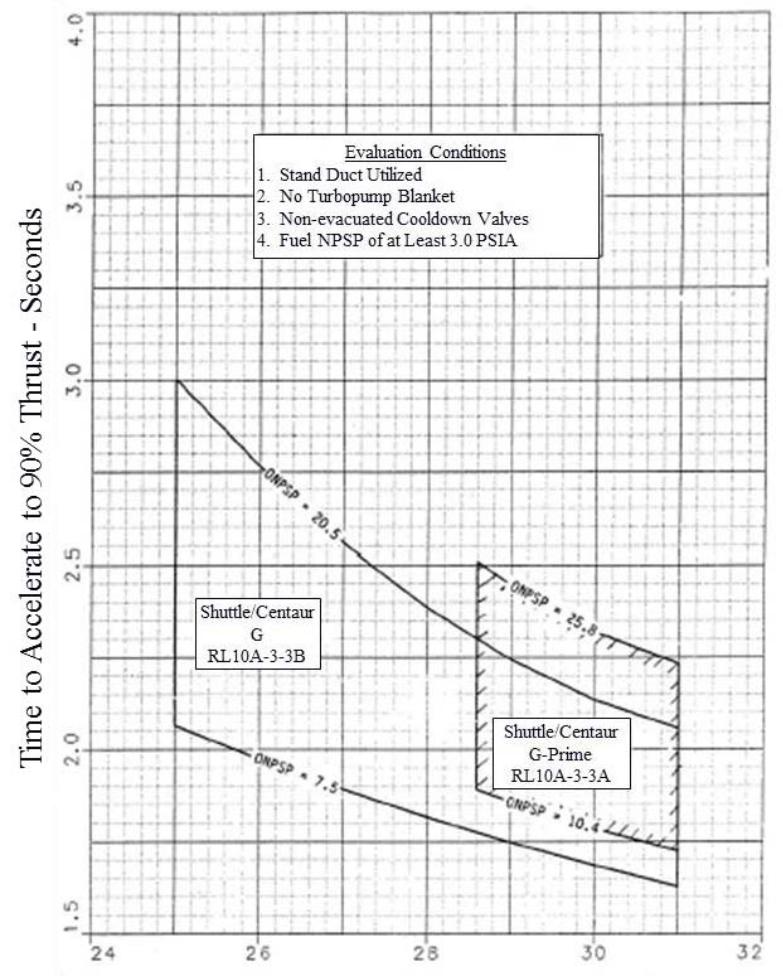

Fuel Pump Inlet Total Pressure - PSIA

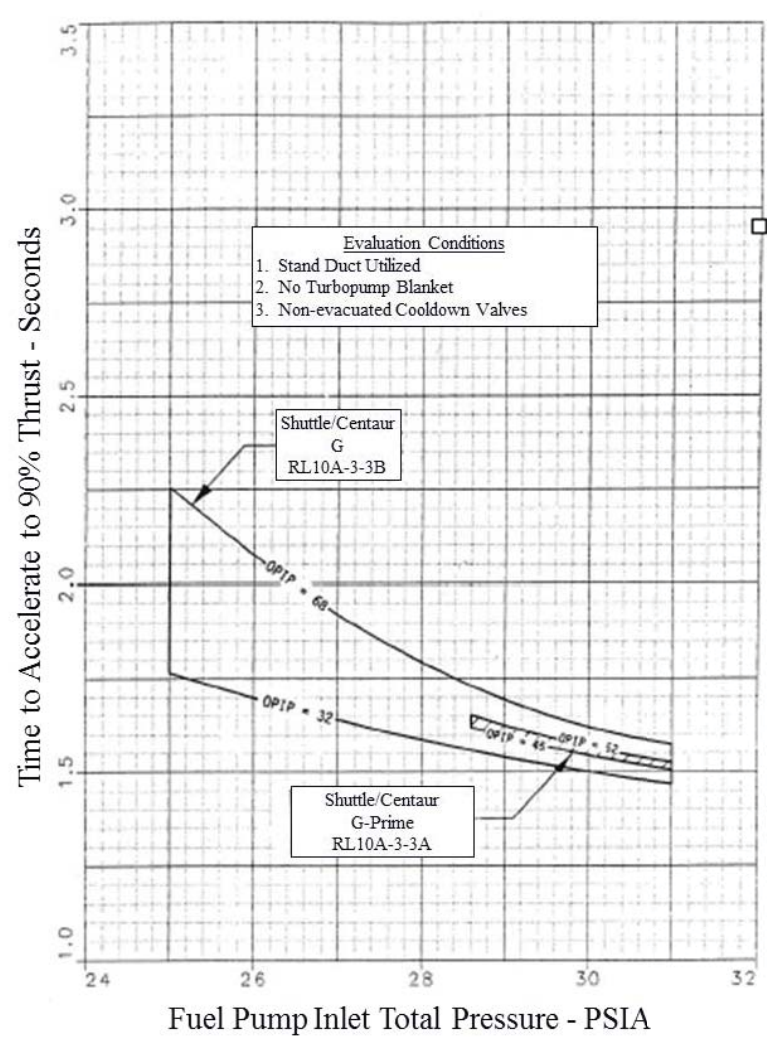

Fuel Pump Inlet Total Pressure - PSIA

\section{Figure 13. Predicted Shuttle/Centaur Engine Acceleration Envelope,}

Original Cooldown Areas (Left), Reduced Cooldown Areas (Right).

Figures 12 and 13 reveal that Centaur vehicle and mission modifications along with small engine changes resulted in a variety of significant engine outcomes. Figure 13 shows the RL10A-3-3A and RL10-3-3B engine time to accelerate impacts on all Centaur vehicles for both the original and reduced cooldown areas. The reduced cooldown area changes improved engine acceleration times. Note in Fig. 13 that the time to accelerate for engines with the reduced cooldown area correlated with Oxidizer Pump Inlet Pressure (OPIP) rather than Oxidizer Net Positive Suction Pressure (ONPSP) as it did for the original cooldown areas.

With the Centaur $G$ vehicle potentially having very long coast times prior to geosynchronous orbit boost, the heating rates for the oxidizer tank (no orbit vent capability) caused a large range of possible oxidizer inlet temperatures (may cool or heat during the orbit duration). This produced much larger inlet start conditions and required longer cooldown times with impractical propellant consumption levels. For the $\mathrm{G}$ vehicle, instead of having a single cooldown time to produce the temperature profile for the oxidizer, it was proposed that the cooldown time would be dependent on the tank saturation pressure at prestart. The cooldown time would then decrease as the inlet saturation pressure increased which minimized the propellant flow times.

Shuttle/Centaur engine restart cooldown times could be shorted due to propellants being in the ducts and the metal parts being near operating temperatures. These conditions were similar to the Atlas/Centaur restart operations.

This prestart cooldown test program resulted in redefining the engine start conditions and small hardware changes to allow for consistent engine start while consuming the smallest amount of propellant. This resulted in the recommendation for a minimal first flight cooldown time with a $10 \%$ margin as listed in Table 5. It is worth noting that the flow of cooldown propellant provides a small impulse to the vehicles. These cooldown times were considerably longer than the Atlas/Centaur with oxidizer and fuel flowing for nine and five seconds respectively. 
Table 5. Nominal Shuttle/Centaur Engine Start Requirements.

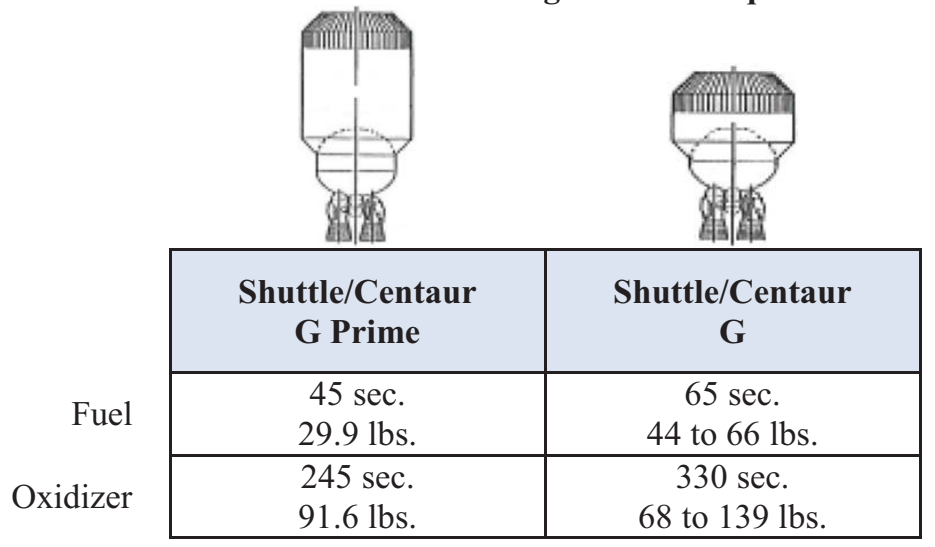

\section{B. RL10A-3-3B Qualification Testing}

The RL10A-3-3B Qualification Test was conducted during the period of March 1985 through January 1986. Testing was performed on two engines using similar procedures as the RL10A-3-3A qualification test program. ${ }^{6}$ One engine performed hot fire testing and one structural limit testing (high structural loads if the thrust control failed at maximum mixture ratio). The qualification test plan was created to qualify the RL10A-3-3B engine, this included:

- $\quad$ Reduce thrust level, 15,000 pounds instead of 16,500 pounds.

- Operate at a higher nominal mixture ratio $(\mathrm{O} / \mathrm{F})$ of $6.0: 1$ instead of 5.0:1.

- Operate over a wider range of propellant inlet conditions.

- Increase cooldown times with smaller flow areas in both fuel and oxidizer systems to provide more efficient cooldown.

The qualification program included three series of tests using a single development engine.

Series I: Hardware durability and limits testing (23 firings).

Series II: Preliminary qualification testing (26 firings).

Series III: Qualification testing (26 firings).

Testing included pre and post calibration tests. At the end of testing, the engine was disassembled, inspected, and calibrated. Quality engineering reviewed the test data. Figure 14 displays the engine mounted in the RL10 hot fire test stand.

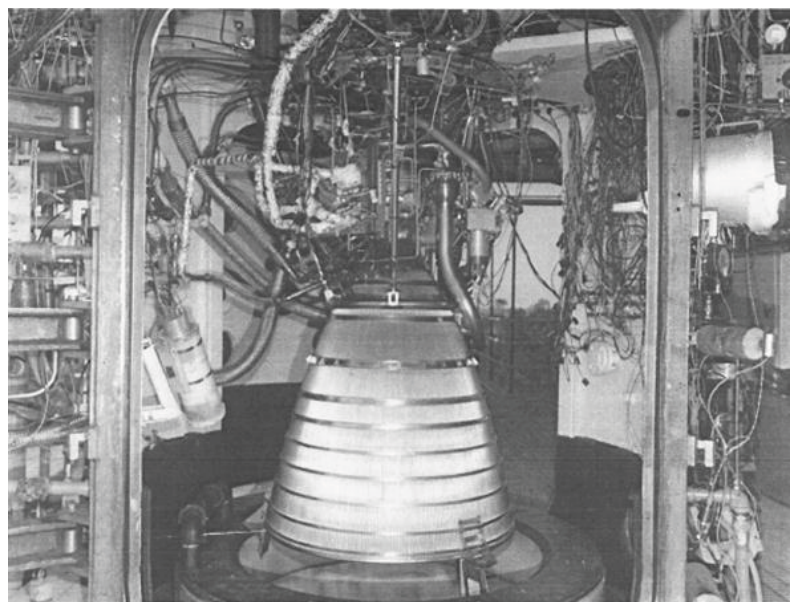

Figure 14. RL10A-3-3B Engine Mounted in the Test Stand.

The RL10A-3-3B successfully completed qualification testing, but testing did produce one engine start anomaly. The objective of that particular hot fire test was to "relight 2 minutes after shutdown of previous run start and steady state inlet conditions". The engine did not light within the allowable time limits. The ignition problem was found to be related to the small cooldown flow area in the oxidizer flow control and inlet conditions which delayed ignition 
beyond the test-stand no-ignition abort time of 0.49 seconds. Shuttle/Centaur configuration reduced the cooldown flow to minimize propellant usage for the smaller tank configuration. This resulted in additional margin being incorporated for the RL10A-3-3B engine for the Shuttle/Centaur Program. It was recommended that a new ignition system be design, built and qualified to eliminate the no-light condition. Subsequent engine testing demonstrated that the no-light encountered during the Qualification Test would have lit on actual flight.

With the exception of the single ignition problem, the engine operated successfully at the higher 6.0:1 mixture within the conditions identified in the engine specification document.

\section{RL10 Vibration Testing}

The environmental loads in the Space Shuttle cargo bay during a launch were significantly different from the well-known Atlas or Titan vehicle loads. A vibration test program was developed to gather vibration data on the engine, the hydraulic actuators, and the engine nozzle plug (Shuttle/Centaur unique). ${ }^{7}$ Testing was conducted during the period of May 1985 through October 1985 and was performed on a single engine using a configuration similar to the Space Shuttle interface, Fig. 15. The test plan was created to:

- Perform sinusoidal and random motion vibration tests on flight like hardware.

- Obtain data for input into NASTRAN model analysis.

- Verify engine durability that included pre and post hot fire testing.

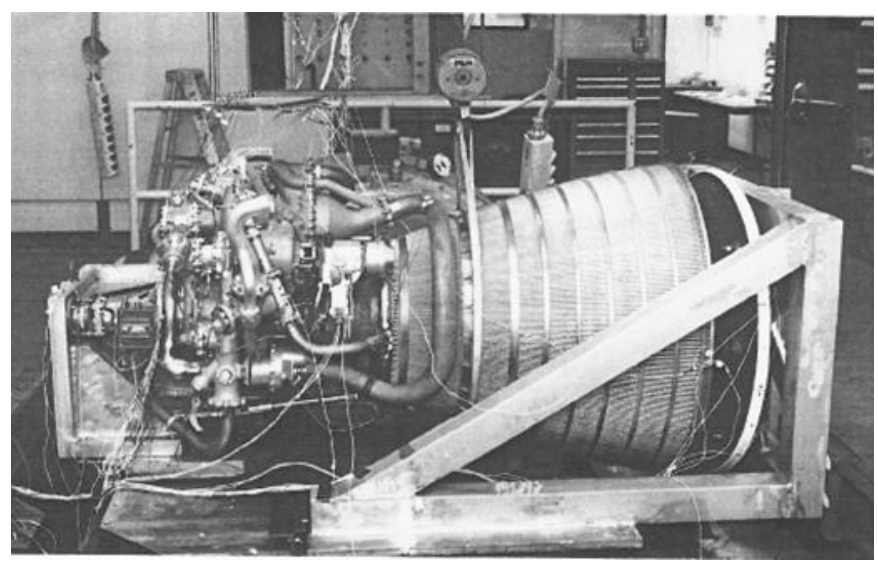

Figure 15. RL10A-3-3B Engine Mounted in the Test Stand.

For the sinusoidal vibration testing, a variety of shaker tests were performed with different configurations of the engine actuators that consisted of sine sweeps from 500 to $5 \mathrm{~Hz}$ (Space Shuttle pitch direction). With the data results provided for the NASTRAN model analysis, engine stresses and actuator loads were deemed well within the limits of the RL10 specification. Therefore, no additional qualification testing was required for the sine vibration. Testing did reveal that self-locking nuts on the nozzle support plug were coming loose and were replaced with safety wire nuts.

For the random motion vibration test, the fixture was modified and consisted of random excitations over the frequency range of 50 to $2000 \mathrm{~Hz}$ for three minutes per axis. For this testing NASA provided detailed directions. Based on the test data results, the engine would survive the proposed random vibration environment. Visual inspection and pre and post hot fire tests showed the engine operated within its expected limits.

The RL10A-3-3A engine successfully completed all vibration testing and verified the engine's ability to operate in the demanding Space Shuttle cargo bay environment for launch and ascent.

\section{RL10 Gimbal Friction Testing}

The RL10 engine gimbal provided the engine thrust load path and bearing system for thrust vectoring to maintain vehicle flight control. This flight control is dependent on the engine actuators, gimbal hardware, and flight control software. With the Shuttle/Centaur introducing a new class of payloads and the 15,000 lbs. thrust engine, a test program was developed to measure the friction characteristics of the engine gimbal friction forces to address flight control concerns. ${ }^{8}$ A test fixture was designed to simulate engine flight thrust load conditions in a thermal vacuum environment. Testing was performed at NASA Lewis Research Center during the period of September 1985 through November 1985, shown in Fig. 16. The test plan was created to: 
- Determine the coulomb friction characteristics (breakaway torque prior to gimbal sliding) of the gimbal system for pitch and yaw axes.

- $\quad$ Simulate 15,000 lbs. thrust load.

- $\quad$ Simulate liquid oxygen tank temperature $\left(175^{\circ}\right.$ Rankin).

- Vacuum up to $10^{-8}$ torr.
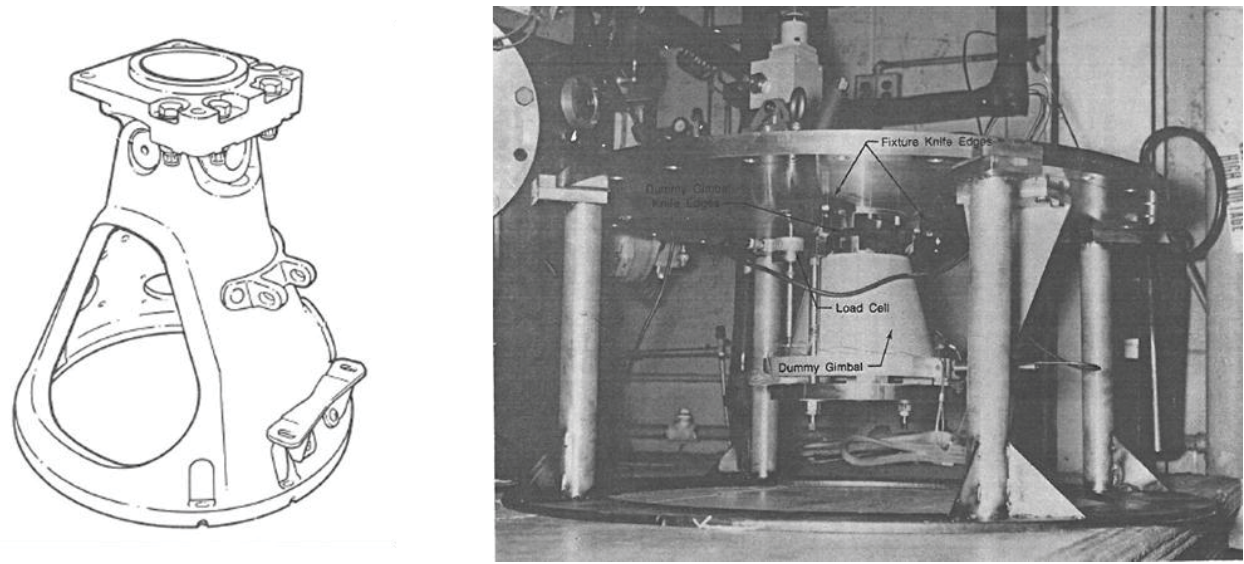

Figure 16. Engine Mount Gimbal Assembly (Left) and Dummy Gimbal Install in Bell Jar Text Fixture (Right).

The gimbal assembly consisted of a conical engine mount, a pedestal, and a spider block incorporating a drylubricated journal bearing. After a total of 32,000 cycles were run, the test fixture performed as expected. Final results showed that the gimbal had elastic characteristics and the coulomb friction levels were significantly lower (40 to $60 \mathrm{ft}-1 \mathrm{lb}$ for production gimbals) from the RL10A-3-3A $220 \mathrm{ft}-\mathrm{lb}$ design specification. The decrease in environmental conditions also had a small effect on decreasing torque required to initiate gimbal sliding. Upon completion, low amplitude and low frequency gimbal friction data was incorporated into autopilot performance studies.

\section{E. RL10 Ignition Limits Testing}

With the Shuttle/Centaur Program introducing new propellant inlet conditions, a proposed change to provide consistent propellant flow to the engine igniter over the broader range of inlet conditions was introduced. This was the result of the no-light conditions during RL10A-3-3B testing. ${ }^{9}$ To address this concern a test plan was created to:

- Perform ignition limits testing to characteristics of the engine igniter mixture ratio over a wide range of propellant inlet conditions.

- Investigate methods to correct potential problems.

Final results showed that there was a need to increase the engine igniter mixture ratio (hardware modifications to increase igniter oxygen flow) to ensure that the igniter performed successfully. This resulted in igniter pluming and igniter leakage control modifications and successful engine ignition throughout the broader propellant inlet range.

Testing also provided valuable insight to warrant further investigation on cooldown valves discharge conditions that provided a more accurate engine start condition. During typical hot fire tests, the cooldown valves were not operated at vacuum conditions due to the possibility of water contamination in the engine from the steam ejector that provided the vacuum. It became evident that hot fire testing, when the cooldown values were vented to a vacuum (Shuttle/Centaur flight environment), was more demanding and could induce no light conditions. Testing revealed that a more favorable start condition was present without the vacuum. Additional tests were to be performed, but were not fully completed due to the cancellation of the Shuttle/Centaur Program.

\section{F. RL10 Ignition System Environmental Testing}

The RL10 engine ignition system contained an exciter assembly (box) that is hermetically sealed with an internal pressure between 20 and 35 psia to prevent electrical breakdown when exposed to vacuum conditions. This pressure is monitored by micro-switches within the exciter box. The Shuttle/Centaur dual pressure switch system is electronically similar to the Atlas/Centaur single pressure system configuration. With the Shuttle/Centaur Program 
functioning under new environmental operating conditions, a test program was developed to verify the ignition pressure switches and system performance. ${ }^{10}$ The test plan was created to:

- Determine how the system would operate at temperatures down to $-300^{\circ} \mathrm{F}$ (design requirement is $-180^{\circ} \mathrm{F}$ ).

- Identify temperature conditions the pressure switches will open at (normally closed when internal pressures are greater than $20 \mathrm{psia})$.

- Identify internal box pressure when exciter fails.

- $\quad$ Correlate exciter box external temperature to internal pressure.

- Use a surplus development test unit that was manufactured in March 1966 (20 years old).

The goal of the testing was to provide a much broader understanding of the pressure switch operations (open and close conditions) and exciter assembly. As testing was underway, several factors became evident that influenced the results and complicated data interpretation. This included:

- System testing of hardware outside its design specifications made it hard to draw conclusions from its unpredictable operations.

- The 20 year old unit appeared to operate unpredictably (exciter open and close lagged with both temperature and pressure).

- Pressure switch performance below the specified $-160^{\circ} \mathrm{F}$ requirement was less than operational minimums.

- Exciter spark rate operated at $-225^{\circ} \mathrm{F}$ but was below specification at $-275^{\circ} \mathrm{F}$ and barely fired at $-300{ }^{\circ} \mathrm{F}$. This was presumed to be from the worn condition of the gas tube rectifier.

- The test unit ultimately failed when internal pressured dropped to 3.2 psia (well below specification).

- Data collected to correlate exciter box external temperature to internal pressure was erratic and inconclusive.

The testing had no impact on the program but did provide a better understanding of the hardware and the testing procedures. Additional testing was recommended if the engine ignition system may operate below $-225^{\circ} \mathrm{F}$.

\section{Shuttle/Centaur Program Impacts on the RL10 Engine}

Developing the RL10 engine for the Shuttle/Centaur Program presented the manufacturer with the challenges of supporting multiple vehicle platforms, different engine configurations, and new human space flight requirements. The Shuttle/Centaur Program resulted in two new RL10 Engine Specification Documentations, a new RL10A-3-3A that accommodated both Atlas/Centaur and Shuttle/Centaur applications and the RL10A-3-3B for the unique Shuttle/Centaur G application. Even though both the Atlas/Centaur and Shuttle/Centaur refer to a common RL10A3-3A engine, different hardware and operating conditions were required.

Designing and ground testing the RL10 for the Shuttle/Centaur Program resulted in several small hardware modifications and operational changes for the engine. These changes included adding a redundant pressure switch in the ignition system, reducing the oxidizer flow control cooldown area, and changing the helium plumbing to improve fuel pump cooldown efficiency. Even with small hardware and operational modifications, considerable changes were introduced from the heritage Atlas/Centaur proficiency, Table 6.

Table 6. Shuttle/Centaur Propulsion Changes.

\begin{tabular}{|l|c|}
\hline \multicolumn{1}{|c|}{ Engine Related Elements } & $\begin{array}{c}\text { Effect on } \\
\text { Shuttle/Centaur }\end{array}$ \\
\hline Performance, steady-state thrust and specific impulse (RL10A-3-3B) & Change \\
\hline Propellant Inlet Conditions & Change \\
\hline Prelaunch Propellant Engine Interface & Change \\
\hline Prelaunch Cooldown & Change \\
\hline Boost Flight Phase & Change \\
\hline Shuttle/Centaur Separation / Deployment & New \\
\hline Prestart & Change \\
\hline Start & No-Change \\
\hline Steady State and Shutdown & No Change \\
\hline Restart & No Change \\
\hline Mission Aborts & New \\
\hline Electrical Power, for propellant valve control & No Change \\
\hline Ignition & Change \\
\hline
\end{tabular}




\begin{tabular}{|l|c|}
\hline Pneumatic Power, for engine operations & No Change \\
\hline Propellants, propellant feed systems operation limits & No Change \\
\hline Thermal Control (precooling prior to engine start) & Change \\
\hline Instrumentation & No Change \\
\hline Hydrogen gas bleed for fuel tank pressurization & No Change \\
\hline Ventage and leakage for propellants and pneumatics interfaces & Change \\
\hline Support equipment, nozzle support plugs \& removable desiccant containers & New \\
\hline External Cleanliness & New \\
\hline Propellant Contaminant Limits (adjusted for larger tank \& operating time) & Change \\
\hline
\end{tabular}

\section{Shuttle/Centaur Termination}

On January 28, 1986, shortly before the first Shuttle/Centaur launch, Space Shuttle Challenger mission STS-51L broke apart 73 seconds into its flight, leading to the tragic loss of its seven crew members. The disaster resulted in a lengthy accident investigation and a 32-month hiatus in the Space Shuttle Program. As a result of this accident, the Shuttle/Centaur Program was terminated. With the program termination, both NASA and the United States Air Force lost the ability to launch heavier and larger spacecraft and take advantage of a unique deployment system. With the United States Air Force's need for increased launch capabilities, they took over the Shuttle/Centaur GPrime development and applied it to the Titan booster. This resulted in the new Titan IV (401A/B) vehicle with the 14 foot diameter hydrogen tank Centaur.

\section{Summary}

The key Shuttle/Centaur Program design feature was to transition the existing Atlas/Centaur RL10 engines to meet this bold and radical concept of launching a Centaur rocket from the Space Shuttle cargo bay. To optimize the Space Shuttle launch capabilities, two Shuttle/Centaur configurations were developed (Centaur G and G-Prime). Utilizing the Atlas/Centaur heritage hardware and expertize provided the program a path with minimal risk. With the repurposing of existing flight hardware and demanding launch window requirements, justifications that minimized hardware testing could have resulted. Management's decision to verify and validate key components and systems is a testament to truly understanding that heritage hardware for new application has built in uncertainties and risks. The versatility of the RL10 engine resulted in the qualification of two new RL10 engine configurations in record time and with human rated flight capabilities.

The Shuttle/Centaur RL10 engine ground test program provided valuable information that included:

- A new understanding of engine and duct prestart cooldown conditions and constraints. Hardware modifications were implemented.

- The engine mixture ratio change did result in an engine start anomaly. This was related to cooldown flow areas; hardware modifications were implemented.

- Vibration testing revealed self-locking nuts on the new nozzle support plug were coming loose. Hardware modifications were implemented.

- Gimbal assembly coulomb friction levels were significantly lower for the new RL10A-3-3B engine. Software changes were implemented.

- Engine igniter mixture ratio needed to be increased to ensure igniter performance for all RL10 engines.

- Identified a small igniter leakage that resulted in a design change.

- Uncovered engine test stand testing conditions that misrepresented flight conditions.

- Provided a broader understanding of the exciter box pressure switch operations and testing procedures.

The majority of these findings required implementing engine modifications. But testing also provided the confidence that the RL10 engine was well suited to meet the Shuttle/Centaur missions. Ground testing provided value added insight into the new engine operating conditions, whereas a flight demonstration test would not have.

\section{Conclusion}

To meet the bold and radical concept of launching a Centaur rocket from the Space Shuttle cargo bay, the Shuttle/Centaur Program reconfigured the Centaur vehicle to be stowed in the Space Shuttle cargo bay and deployed in low earth orbit. Incorporating the Centaur vehicle into the Space Shuttle provided an attractive and relatively simple approach to enhanced boost capacity and provided both NASA and United States Air Force with unique deployment capabilities. To meet the Shuttle/Centaur Program goals that included cost, safety, reliability, schedule and technical requirements, the integration of the Centaur with the Space Shuttle needed to retain the vast majority 
of the existing Centaur hardware. A key program design feature was the ability to transition the existing Atlas/Centaur RL10 engine.

Upgrading the Centaur to accommodate the Space Shuttle human space flight requirements was the primary concern. Leveraging from the successful Atlas/Centaur vehicle heritage was a factor in reducing program development time, testing, and risk. The ability of the RL10 engine to transition to the Shuttle/Centaur configurations with limited modifications showed the engine architecture's unique versatility and capability.

The Shuttle/Centaur Program required the engine to quickly accommodate new operating and environmental conditions with minimal hardware changes. The RL10 engines long proven flight record and what may have seemed like trivial engine modifications was extremely valuable for program conceptualization and definition. But the added value and risk reduction of actual component and system ground testing provided critical information that a flight demo would have missed. This was evident from the Shuttle/Centaur RL10 testing outcomes. It also provided the opportunity to truly learn how the hardware performed outside its original design specifications and identified new capabilities and operating limits. It also gave both new and experienced engineers testing and operating experiences as-well-as exposure to good engineering practices. It also provided valuable hands-on experience and confidence to apply knowledge and lessons learned for time critical launch decisions.

In hindsight, the RL10 engine was well suited to accommodate the Shuttle/Centaur missions with its capabilities, flexibility and durability. But testing of heritage hardware applied to new missions provided a valuable learning opportunity and ideal approach to accurately comprehend both verification and validation requirements. Without the ground test activities, the highest levels of safety and reliable would have never been achieved and future applications would have lost the benefits of knowledge gained.

\footnotetext{
${ }^{1}$ Stofan, A.J., “A High Energy Stage for the National Space Transportation System,” NASA TM-83795, 1984.

2 "RL10 Liquid Rocket Engine, Service Manual, Model RL10A-3-3A," Pratt and Whitney Aircraft, Feb. $15,1982$.

3 "Model Specification Rocket Engine, Liquid Propellant Pratt \& Whitney RL10A-3-3A Atlas/Centaur and Shuttle/Centaur Application," Pratt and Whitney Aircraft, April 11, 1985.

4 "Model Specification Rocket Engine, Liquid Propellant Pratt \& Whitney RL10A-3-3B Shuttle/Centaur Installation," Pratt and Whitney Aircraft, April 11, 1985.

5 "NASA Final Report on all Shuttle/Centaur Engine and Nozzle Support Plug Vibration Testing," United Technologies Corporation, Pratt \& Whitney, NASA Contract NAS3-23791, May 1987.

${ }^{6}$ Vogel T., Varella D., Smith C., "NASA RL10A-3-3B High Mixture Ratio Qualification Program, Final Report," United Technologies Corporation, Pratt \& Whitney, NASA Contract NAS3-22902, May 1987.

7 "NASA Final Report on all Shuttle/Centaur Engine and Nozzle Support Plug Vibration Testing," United Technologies Corporation, Pratt \& Whitney, NASA Contract NAS3-23791, May 1987.

8 "NASA RL10 Gimbal Friction Test, Final Report," United Technologies Corporation, Pratt \& Whitney, NASA Contract NAS323313, May 1987.

9 "NASA RL10 Ignition Limits Test for Shuttle/Centaur, Final Report," United Technologies Corporation, Pratt \& Whitney, NASA Contract NAS3-22902, May 1987.

10 “NASA RL10 Ignition System Environmental Testing, Final Report," United Technologies Corporation, Pratt \& Whitney, NASA Contract NAS3-23791, May 1987.
}

Trade names or manufactures names are used in this report for identification only. This usage does not constitute an official endorsement, either expressed or implied, by the National Aeronautics and Space Administration. 